\title{
STUDI PERMASALAHAN TITIK BANJIR PADA DRAINASE SEKUNDER DI KECAMATAN BLAHBATUH, KABUPATEN GIANYAR, PROVINSI BALI
}

\author{
Sagung Putri Chandra Astiti \\ Program Studi Teknik Industri, Fakultas Teknik, Universitas Mahendradatta \\ Jl. Ken Arok No.12, Peguyangan, Denpasar, Bali 80115 \\ Email: sagungchandra17@gmail.com
}

\begin{abstract}
Abstrak - Permasalahan banjir masih menjadi dilema dalam kehidupan masyarakat, karena dapat menyebabkan hal yang merugikan seperti adanya penyakit, aktifitas kegiatan yang terganggu, dan hal lainnya. Hal ini perlu mendapat perhatian dan penanganan yang serius dalam segenap komponen masyarakat yang ada agar permasalahan banjir tidak menjadi ancaman yang menakutkan untuk kelangsungan hidup kedepannya. Permasalahan banjir pada umumnya masih menjadi permasalahan serius dalam suatu wilayah, dimana dalam hal ini permasalahan banjir yang diteliti yaitu permasalahan dalam Kecamatan Blahbatuh.

Tingginya tingkat aktifitas serta kepadatan penduduk di Kecamatan Blahbatuh menyebabkan pentingnya penyediaan sarana dan prasarana yang memadai. Penyediaan sarana dan prasarana untuk menunjang aktifitas tersebut, salah satunya yang sangat diperlukan adalah penyediaan saluran drainase yang tepat dan aman dalam penggunaannya. Drainase memiliki peranan yang sangat penting dalam membawa aliran air menuju saluran pembuangan, sehingga permasalahan banjir yang menghambat aktifitas kegiatan masyarakat dapat diminimalisir. Untuk memberikan penanganan yang tepat, hal yang harus dilakukan yaitu mengetahui jenis permasalahan yang ada, dimana dalam hal ini salah satu permasalahan banjir disebabkan oleh permasalahan pada drainase sekundernya.
\end{abstract}

Kata kunci: Drainase Sekunder, Kecamatan Blahbatuh, Titik Banjir

\begin{abstract}
The problem of flooding is still a dilemma in people's lives, because it can cause adverse things such as disease, disrupted activities, and other things. This needs serious attention and handling by all components of society so that the problem of flooding does not become a frightening threat for future survival. In general, the problem of flooding is still a serious problem in an area, where in this case the flood problem being studied is the problem in Blahbatuh District. The high level of activity and population density in Blahbatuh District make the provision of adequate facilities and infrastructure important. Provision of facilities and infrastructure to support these activities, one of which is indispensable is the provision of drainage channels that are appropriate and safe in their use. Drainage has a very important role in bringing water flow to the sewer, so that the problem of flooding that hinders community activities can be minimized. To provide proper treatment, what must be done is to know the types of problems that exist, where in this case one of the flood problems is caused by problems with secondary drainage
\end{abstract}

Keywords: Blahbatuh District, Flood Spot, Secondary Drainage

\section{PENDAHULUAN}

Kecamatan Blahbatuh merupakan salah satu kecamatan yang berada di Kabupaten Gianyar dengan lokasi koordinat yang berada pada 8 $31^{\prime} 09^{\prime \prime}$ - 8035'58" LS dan 115016'59,7' $115^{\circ} 21$ '21,7" BT serta memiliki luas wilayah sebesar $39,70 \mathrm{~km}^{2}$. Kecamatan Blahbatuh memiliki 9 Desa yaitu Desa Saba, Desa Pering, Desa Keramas, Desa Medahan, Desa Bona, Desa Belega, Desa Blahbatuh, Desa Buruan dan Desa Bedulu (Kecamatan Blahbatuh dalam Angka,2019). Tingginya jumlah penduduk dari tahun ke tahun serta terjadinya perubahan penggunaan lahan menjadi kawasan pemukiman menimbulkan beberapa permasalahan, salah satunya yaitu timbulnya banjir akibat berkurangnya daerah resapan.

Tingginya aktivitas kegiatan penduduk yang tidak diimbangi dengan penyediaan sarana prasarana drainase yang memadai serta kurangnya tingkat disiplin masyarakat dalam pengelolaan maupun pembuangan sampah merupakan salah satu penyebab terjadinya banjir. Saluran drainase yang kehilangan fungsinya akan mengalami penurunan fungsi, dimana saluran drainase tersebut tidak akan mampu menyalurkan air pada saat terjadi 
hujan deras. Lahan yang tidak dimanfaatkan dan dikelola dengan tepat dan tertib akan mempengaruhi perencanaan drainase dari segi dimensi sehingga fungsi drainase tidak dapat berjalan secara maksimal (Amalia,2012).

Permasalahan yang timbul akibat terjadinya banjir akan mempengaruhi kelancaran lalu lintas aktifitas masyarakat, serta menimbulkan kerusakan pada jalan akibat genangan air yang terjadi pada kurun waktu tertentu. Permasalahan banjir menjadi persoalan yang harus mendapatkan perhatian dari segenap komponen masyarakat, sehingga permasalahan tersebut tidak menjadi dilema yang berkepanjangan. Berdasarkan beberapa analisis dari persoalan banjir pada umumnya, banjir diakibatkan oleh ketidakmapuan sistem drainase mengalirkan air pada saluran yang ada sehingga menimbulkan titik genangan pada jalan raya.

Timbulnya endapan dan tumpukan sampah pada saluran drainase akan mengakibatkan tingginya tingkat kompleksitas pada saluran drainase yang ada, sehingga kesadaran dan kedisiplinan segenap komponen masyarakat maupun pemerintahan sangat diperlukan (Syapawi,2014). Peran edukasi, penyuluhan serta pembersihan rutin untuk saluran drainase menjadi salah satu alternatif untuk mengurangi tingkat kompleksitas yang ada, sehingga segenap komponen masyarakat juga menyadari akan pentingnya merawat suatu fasilitas penunjang yang telah disediakan.

Drainase memiliki fungsi yang sangat berkaitan erat dengan penanganan luapan air dimana fungsi dari drainase yaitu untuk mencegah atau meminimalisir terjadinya genangan yang dapat mengganggu kegiatan transportasi, menampung, membagi dan mengalirkan air hujan menuju saluran pembuangan akhir, mencegah aliran air masuk ke dalam perkerasan jalan, dan memperindah estetika dalam suatu kota. Keberhasilan suatu fungsi drainase ditentukan oleh pemilihan dimensi yang tepat, kemudahan, keamanan dan sisi ekonomis dari drainase tersebut (Syapawi,2013).

\section{METODOLOGI}

Dalam mengidentifikasi permasalahan pada suatu sistem drainase yang ada, beberapa metode kegiatan yang dilakukan adalah sebagai berikut :

a. Mengumpulkan informasi mengenai titik banjir dari dinas terkait, informasi masyarakat sekitar maupun informasi dari sosial media seperti artikel berita tentang kejadian banjir di lokasi penelitian

b. Membuat titik- titik banjir yang ditampilkan dalam bentuk peta sehingga peninjauan lokasi lebih mudah untuk dilaksanakan

c. Menyiapkan meteran untuk mengukur dimensi saluran yang ada

d. Menyiapkan alat Global Positioning System (GPS) untuk mencatat titik koordinat pada titik lokasi yang ditinjau.

e. Menyiapkan kamera sebagai bukti dokumentasi kegiatan lapangan.

Pengumpulan informasi berupa studi literatur, informasi dari dinas terkait, informasi masyarakat serta informasi dari sosial media sangat diperlukan dalam pengidentifikasian permasalahan yang ada dalam lokasi penelitian. Setelah titik-titik informasi tersebut didapatkan, selanjutkan dilakukan proses pemasukan data ke dalam bentuk peta agar lebih mudah dipahami. Pembuatan peta dilakukan menggunakan software ArcGIS 10.2.2.

Setelah dibuatkan peta, selanjutkan dilakukan peninjauan ke lokasi guna mengindentifikasikan permasalahan yang ada, dilengkapi dengan pengukuran penampang saluran untuk mendapatkan informasi mengenai dimensi saluran dan penggunaan Global Positioning System (GPS) untuk mengetahui titik koordinat pada saluran yang mengalami permasalahan. Titik banjir dari drainase yang ditinjau pada Kecamatan Blahbatuh merupakan drainase sekunder dalam pemanfaatannya. Pemilihan titik lokasi juga didasarkan pada titik kejadian yang paling sering terjadi, khususnya pada kondisi jalan utama yang berada di lokasi penelitian. 


\section{HASIL DAN PEMBAHASAN}

Berikut ini merupakan gambaran umum mengenai batasan wilayah berupa batas administrasi, batas jalan beserta sungai yang berada di Kecamatan Blahbatuh yang ditampilkan dalam bentuk Gambar 1.

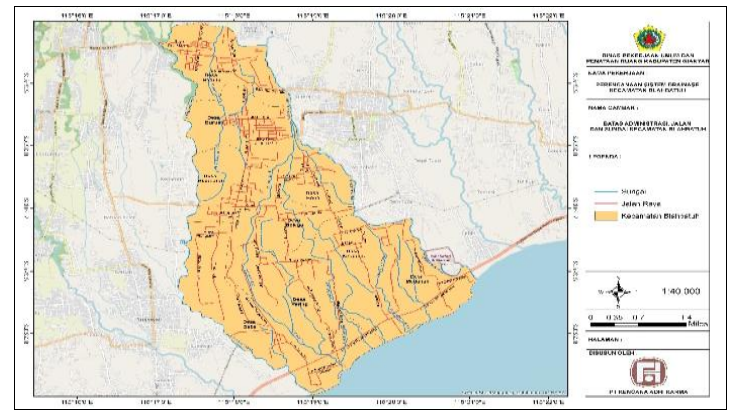

Gambar 1. Batas Administrasi Kecamatan Blahbatuh

Adapun sungai yang terdapat dalam Kecamatan Blahbatuh adalah Tukad Petanu, Tukad Jurang, Tukad Kutul, Tukad Sangku, dan Tukad Pakerisan. Berdasarkan data yang diperoleh, titik-titik banjir yang berada di Kecamatan Blahbatuh terdapat pada Jl.Pantai Saba, Jl.Gunung Batur, Jl. Raya Tojan, Jl.Raya Bona, JI.Raya Belega dan JI. Udayana. Titiktitik banjir tersebut akan ditampilkan dalam bentuk Gambar 2.

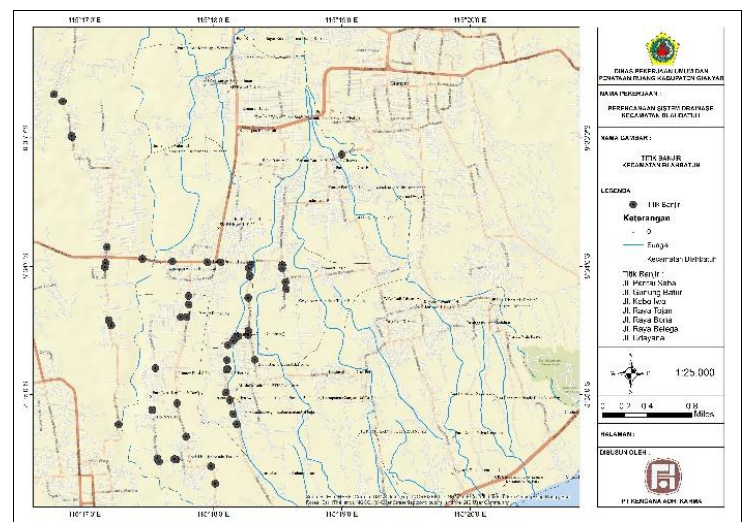

Gambar 2. Titik Banjir Kecamatan Blahbatuh

Hasil pengamatan di lokasi menunjukkan bahwa kondisi saluran di JI.Pantai Saba dalam kondisi kurang terawat, yaitu dengan kondisi banyaknya tumpukan sampah di saluran, serta belum adanya pasangan batu kali atau beton untuk saluran tersebut. Sampah yang mencemari saluran mengakibatkan fungsi drainase tidak berjalan secara optimal karena menghambat aliran air yang terdapat dalam saluran tersebut. Pasangan batu dalam saluran berfungsi sebagai penyangga untuk mencegah terjadinya longsor pada dinding saluran akibat aliran air yang deras. Dimensi saluran pada Gambar 3 tersebut yaitu $90 \mathrm{~cm}$ (Lebar Bawah), $90 \mathrm{~cm}$ (Lebar Atas) dan $90 \mathrm{~cm}$ (Tinggi Saluran), berada pada titik koordinat $8^{0} 35^{\prime} 31,4$ " LS dan $115^{\circ} 17^{\prime} 32,4^{\prime \prime}$ BT.

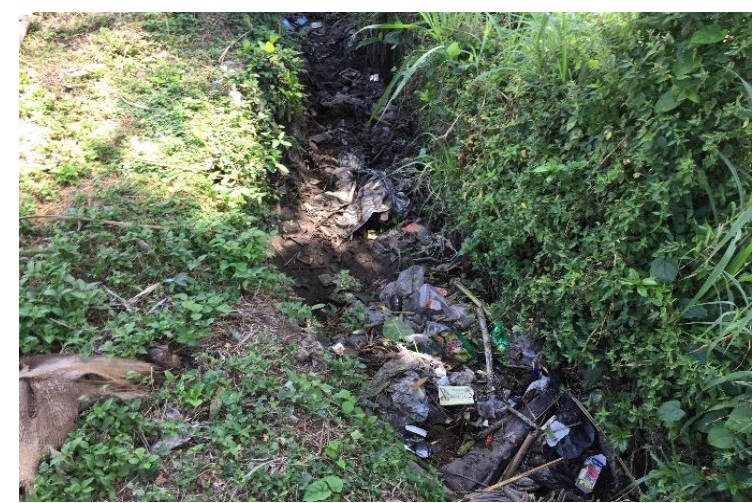

Gambar 3. Kondisi Saluran di JI.Pantai Saba

Hasil pengamatan di lokasi menunjukkan bahwa kondisi saluran di Jl.Gunung Batur dalam kondisi saluran dengan endapan pasir dan sedimentasi. Hal ini diakibatkan oleh sedimen yang terbawa aliran sehingga mengendap pada lantai saluran. Pembersihan saluran diperlukan agar kemampuan tanah yang ada dalam menyerap air memjadi tidak terhambat. Tinggi saluran dalam saluran ini terlalu dangkal. Dimensi saluran pada Gambar 4 tersebut yaitu $80 \mathrm{~cm}$ (Lebar Bawah), $80 \mathrm{~cm}$ (Lebar Atas) dan $20 \mathrm{~cm}$ (Tinggi Saluran), berada pada titik koordinat $8^{0} 32^{\prime} 41,1^{\prime \prime}$ LS dan $115^{0} 16^{\prime} 44,2$ " BT.

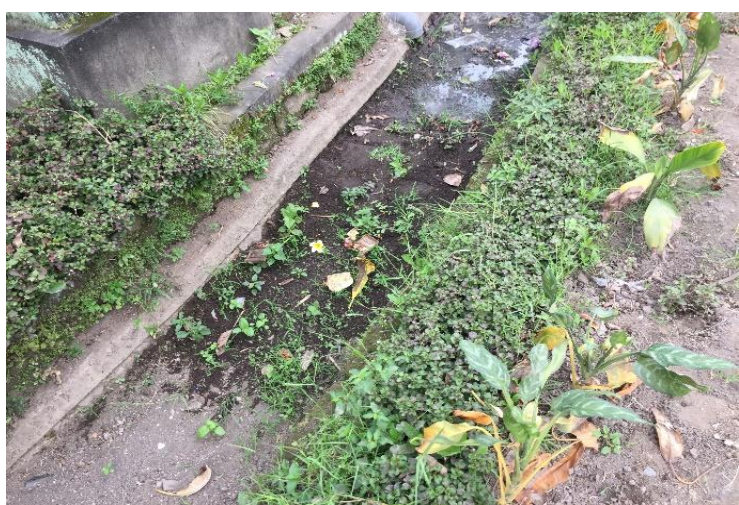

Gambar 4. Kondisi Saluran di JI.Gunung Batur

Hasil pengamatan di lokasi menunjukkan bahwa kondisi saluran di Jl.Raya Tojan dalam kondisi yang kurang terawat, dimana rerumputan liar menghambat aliran air pada 
saluran sehingga kemampuan saluran tidak dapat terlaksana secara maksimal. Pembersihan saluran diperlukan agar saluran dapai membawa aliran air ke tempat pembuangan terakhir secara optimal. Dimensi saluran pada Gambar 5 tersebut yaitu $70 \mathrm{~cm}$ (Lebar Bawah), $70 \mathrm{~cm}$ (Lebar Atas) dan $45 \mathrm{~cm}$ (Tinggi Saluran), berada pada titik koordinat $8^{0} 34^{\prime} 06^{\prime \prime}$ LS dan $115^{\circ} 18^{\prime} 15,6^{\prime \prime}$ BT.

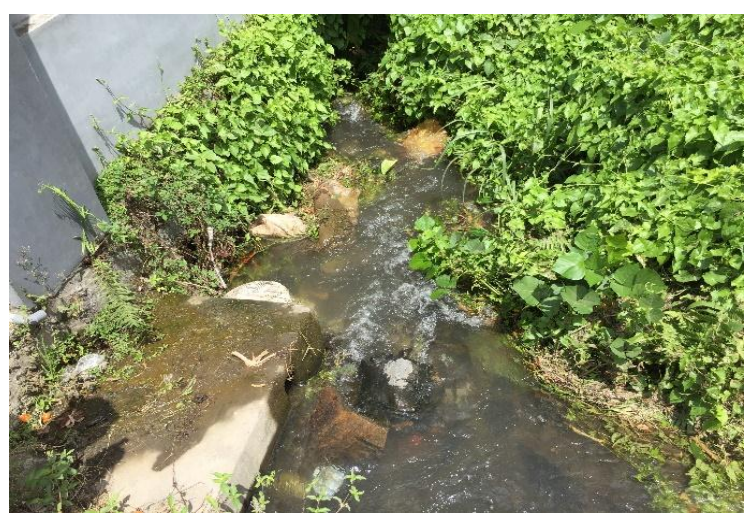

Gambar 5. Kondisi Saluran di JI.Raya Tojan

Hasil pengamatan di lokasi menunjukkan bahwa kondisi saluran di Jl.Raya Bona dalam kondisi yang rusak pada bagian penutup saluran. Tidak terdapat drain inlet pada saluran sehingga air yang tergenang dalam jalan raya tidak dapat masuk ke dalam saluran kembali. Dimensi saluran pada Gambar 6 tersebut yaitu $60 \mathrm{~cm}$ (Lebar Bawah), $60 \mathrm{~cm}$ (Lebar Atas) dan $40 \mathrm{~cm}$ (Tinggi Saluran), berada pada titik koordinat $8^{0} 33^{\prime} 09,3^{\prime \prime}$ LS dan $115^{0} 18^{\prime} 58,5^{\prime \prime}$ BT.

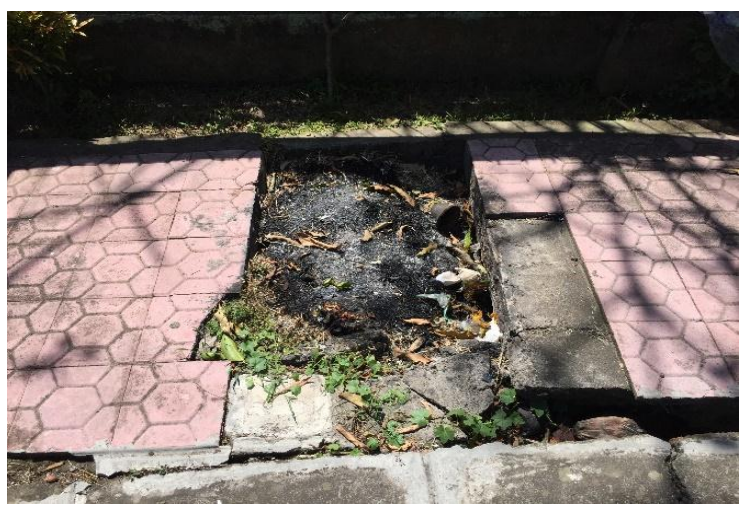

Gambar 6. Kondisi Saluran di Jl.Raya Bona

Hasil pengamatan di lokasi menunjukkan bahwa kondisi saluran di Jl.Raya Belega dalam kondisi yang kurang terawat, dimana rerumputan liar dan sampah menghambat aliran air pada saluran sehingga kemampuan saluran tidak dapat terlaksana secara maksimal. Pembersihan saluran diperlukan agar saluran dapai membawa aliran air ke tempat pembuangan terakhir secara optimal. Dimensi saluran pada Gambar 7 tersebut yaitu $60 \mathrm{~cm}$ (Lebar Bawah), $60 \mathrm{~cm}$ (Lebar Atas) dan $50 \mathrm{~cm}$ (Tinggi Saluran), berada pada titik koordinat $8^{0} 34^{\prime} 08,8^{\prime \prime}$ LS dan $115^{\circ} 18^{\prime} 32,3^{\prime \prime}$ BT.

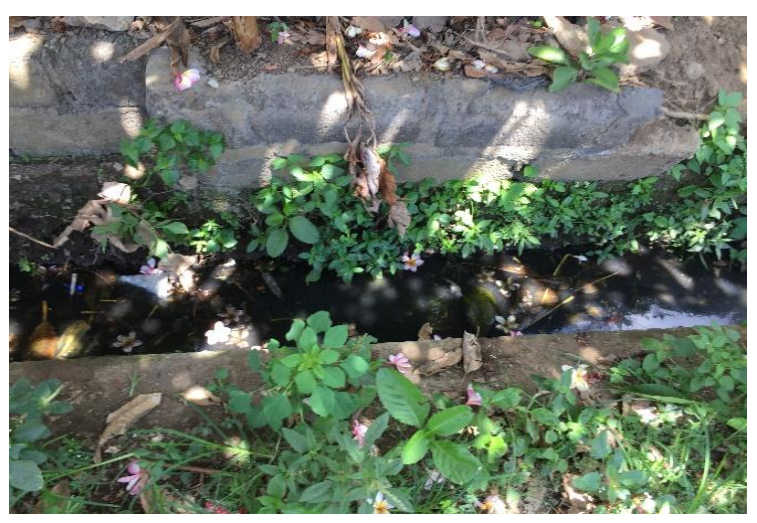

Gambar 7. Kondisi Saluran di Jl.Raya Belega

Hasil pengamatan di lokasi menunjukkan bahwa kondisi saluran di Jl.Raya Udayana dalam kondisi yang rusak pada bagian penutup saluran. Tidak terdapat drain inlet pada saluran sehingga air yang tergenang dalam jalan raya tidak dapat masuk ke dalam saluran kembali. Selain itu, ditemukan sampah dalam saluran sehingga menghambat penyerapan air ke dalam tanah. Dimensi saluran pada Gambar 8 tersebut yaitu $80 \mathrm{~cm}$ (Lebar Bawah), $80 \mathrm{~cm}$ (Lebar Atas) dan $40 \mathrm{~cm}$ (Tinggi Saluran), berada pada titik koordinat $8^{0} 33^{\prime} 59,6^{\prime \prime}$ LS dan $115^{\circ} 17^{\prime} 55,8^{\prime \prime}$ BT.

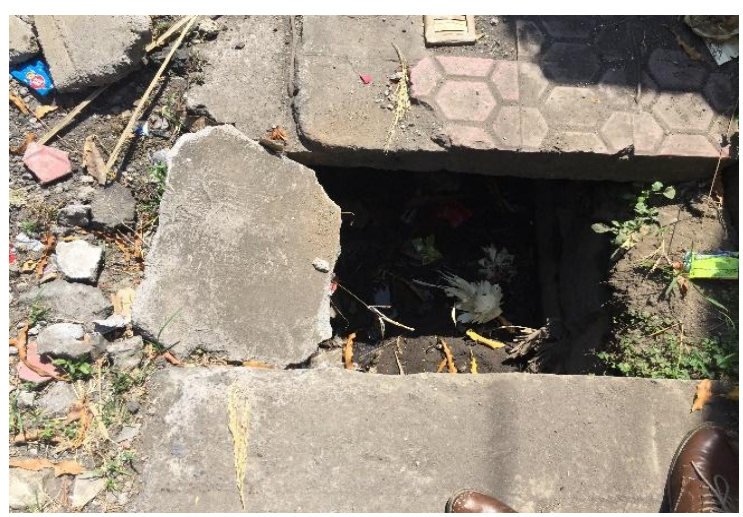

Gambar 8. Kondisi Saluran di Jl.Raya Udayana

\section{KESIMPULAN DAN SARAN}

Berdasarkan hasil pengamatan yang telah dilaksanakan, didapatkan data dan informasi titik banjir yang berada di Kecamatan 
Blahbatuh pada titik Jl. Pantai Saba, Jl.Gunung Catur, Jl. Raya Tojan, Jl. Raya Bona, Jl. Raya Belega dan JI.Udayana. Secara umum, permasalahan titik banjir tersebut berupa kondisi saluran yang kurang terawat seperti banyaknya rerumputan liar pada saluran, terdapat sampah pada saluran, terdapat endapan atau sedimentasi pada saluran, belum adanya pasangan pada dinding saluran untuk mencegah kelongsoran dinding serta tidak terdapat drain inlet pada beberapa saluran di Kecamatan Blahbatuh.

Saran yang dapat penulis berikan untuk menyempurnakan penelitian ini yaitu dilakukannya perencanaan untuk perhitungan kapasitan saluran berupa perencanaan dimensi untuk lebar atas, lebar bawah serta tinggi saluran sesuai dengan metode perhitungan dimensi saluran yang tepat. Perencanaan dimensi saluran tersebut hendaknya memiliki aspek ekonomis, efisien, aman serta tepat dalam penggunaan dan penerapannya.

\section{DAFTAR PUSTAKA}

Amalia S, Oktiawan W. Pengaruh Kondisi Sistem Drainase, Persampahan dan Air Limbah Terhadap Kualitas Lingkungan (Studi Kasus Kelurahan Kuningan Kecamatan Semarang Utara). Jurnal PRESIPITASI. 2012; 9(1): 41-50.

Badan Pusat Statistik Kabupaten Gianyar. Kecamatan Blahbatuh dalam Angka 2019.

Sadewa T,Sutoyo. Kajian Sistem Drainase di Daerah Jalan Pemuda, Kota Bogor. Jurnal Teknik Sipil dan Lingkungan. 2018; 3(3): 111-120.

Silitonga, B. Identifikasi Sistem Drainase Untuk Penanganan Banjir Kota Medan. Jurnal Rekayasa Konstruksi Mekanika Sipil. 2019; 2(1): 35-42.

Syapawi, A. Studi Permasalahan Drainase Jalan (Saluran Samping) Dilokasi Jalan Demang Lebar Daun Sepanjang $\pm 3900 \mathrm{~m}$ (Lingkaran SMA Negeri 10 S.D Simpang POLDA). PILAR Jurnal Teknik Sipil. 2013; 9(2): 143-148.

Syapawi, A. Studi Permasalahan Drainase dan Solusi Air Genangan (Banjir) di Jalan Kemang Manis. PILAR Jurnal Teknik Sipil. 2014;10(2):107-114. 